\title{
Descentralización: una definición y una evaluación de la agenda legislativa chilena (1990-2008) *
}

\author{
RODRIGO MARDONES Z.** \\ ** Profesor Asistente, Instituto de Ciencia Política, Pontificia Universidad Católica de Chile.
}

\begin{abstract}
Starting from a theoretical revision of the concept of decentralization, this paper proposes a definition which underlines the requirement of an effective transferring of power, functions and financial resources to autonomous subnational governments. This definition excludes other phenomena usually presented as decentralization, such as privatization, delegation, deconcentration, and regional and local development. This article offers a novel systematization of legislative bills approved in Chile between 1990 and 2008. The analysis of 174 laws relevant on regional and local matters allows to asses the so called Chilean decentralization process, concluding that its real decentralizing effect is debatable. In addition, the review of the Chilean case compels a revision of the initial working definition.
\end{abstract}

KEYWORDS: federalism, decentralization, municipalities, legislation, Chile

RESUMEN: A partir de una revisión teórica sobre el concepto de descentralización, este artículo propone una definición que subraya la transferencia efectiva de poder, atribuciones y recursos a gobiernos subnacionales autónomos, y que lo distingue de fenómenos usualmente considerados erróneamente como descentralización, como es el caso de la privatización, la delegación, la desconcentración y el desarrollo regional y local. El trabajo ofrece una sistematización inédita de la legislación aprobada en Chile entre 1990 y 2008. El análisis de 174 leyes de impacto regional y comunal permite evaluar el llamado proceso descentralizador chileno, para concluir que su real impacto descentralizador es cuestionable. Adicionalmente, la revisión del caso chileno aporta luces para la reconsideración de la definición inicial.

PALABRAS CLAVES: federalismo, descentralización, municipalidades, legislación, Chile

\footnotetext{
Este artículo fue generado como parte del proyecto FONDECYT 3060031, del cual el autor fue Investigador Responsable.

Recibido el 28 de mayo de 2007, aprobado el 26 de mayo de 2008.

Correspondencia: Rodrigo Mardones, Av. Vicuña Mackenna 4860, Macul, Santiago de Chile. E-mail: rmardonesz@ uc.cl
} 


\section{Introducción}

En el contexto de la ola descentralizadora mundial iniciada a comienzos de los años 80, la descentralización se ha convertido en un requisito para el desarrollo regional y la democracia local. Sin embargo, la política de la descentralización plantea el dilema de que los mismos actores centrales que han de transferir poder a los gobiernos subnacionales deben renunciar unilateral y gratuitamente a sus atribuciones. De este modo, los procesos contemporáneos de descentralización incluyen esfuerzos retóricos que denominan como tales a iniciativas que en realidad no lo son, de manera de aplacar la demanda descentralizadora proveniente de actores subnacionales, mientras se mantiene un férreo control del proceso en términos de su profundidad y ritmo de avance.

A menudo, por ejemplo, los sucesivos gobiernos chilenos han llamado descentralización a iniciativas de desarrollo regional que han sido diseñadas con escasa o nula participación de las autoridades subnacionales. Incluso la apertura en terreno de una oficina del gobierno central es presentada como una iniciativa descentralizadora, cuando en rigor se trata de desconcentración. El mismo tratamiento se ha dado al traspaso de tareas y funciones a los gobiernos municipales, quienes en realidad actúan como proveedores de bienes y servicios públicos, quedando en la práctica el gobierno central como único responsable de fijar estándares, fiscalizar, financiar y evaluar, lo que en realidad corresponde a la modalidad de delegación, muy distinta a una auténtica descentralización.

En cualquier caso, la retórica que utilizan los gobiernos centrales se alimenta de una confusión teórica sobre qué es descentralización, lo cual tiene su origen en el tratamiento académico del problema. Por ende, el objetivo de este trabajo es proporcionar una precisión conceptual sobre este fenómeno, al mismo tiempo que evaluar cuál ha sido el real alcance descentralizador de la agenda legislativa de los gobiernos de la Concertación; la coalición de centro-izquierda en el poder en Chile desde la restauración democrática en 1990.

Para tal efecto, en primer lugar este artículo revisa los orígenes de la descentralización, apuntando a dos principios: el modelo federal (sección 2) y la idea de gobierno local (sección 3). Aunque el primero de estos principios puede parecer a priori particularmente ajeno a la realidad de los países unitarios, este artículo argumenta que, precisamente, en parte son las ventajas de la aplicación del principio del federalismo -sin pasar por un cambio de régimen- lo que los países unitarios intentan capitalizar a través de sus reformas descentralizadoras.

Teniendo en vista tanto el modelo federal como la idea de gobierno local, el artículo ofrece a continuación (sección 4) una definición de trabajo de descentralización de carácter más restrictivo a lo que usualmente se ha considerado como tal, dejando completamente fuera a los procesos de privatización, y precisando que los fenómenos de delegación y desconcentración comparten una lógica general con la descentralización, pero son en definitiva de alcance y naturaleza distinta.

En Chile, los distintos fenómenos considerados (descentralización, delegación, desconcentración, privatización) son materia de ley. Por lo mismo, un primer paso en la evaluación del 
llamado "proceso de descentralización" en este país es el análisis del alcance descentralizador de la legislación aprobada. Por cierto, la evaluación del proceso no se agota en el análisis legislativo; una evaluación integral debiera complementarse con un análisis de la praxis y de la política de la reforma. La evaluación de la praxis ha sido abordada en variados estudios en sus distintas dimensiones (educación, salud, etc.), mientras que el tema de la política de la reforma ha sido investigado en detalle por el propio autor de este artículo (ver Mardones 2006 y 2007). Con todo, el primer componente de análisis legislativo no ha sido realizado, y por tanto se constituye en el principal aporte empírico del presente trabajo.

De este modo, el componente empírico del artículo (sección 5) sistematiza la legislación chilena en función de las categorías mencionadas. Después de una investigación exhaustiva de fuentes legislativas que comprende el período desde el 11 de marzo de 1990 al 11 de julio de 2008 (desde la restauración democrática al presente), se ha definido un conjunto de 174 leyes, cuyo contenido específico está relacionado directamente con asuntos regionales y/o locales, y que podría señalarse corresponden a lo esencial del proceso descentralizador chileno durante los gobiernos de la Concertación. Al revisar los textos de estas leyes se ha tenido en cuenta la definición de descentralización finalmente adoptada de manera de clasificarlas y, en definitiva, evaluar el real alcance descentralizador de este proceso.

El trabajo empírico vuelve a plantear ciertos desafíos a la definición, por ejemplo el problema de si crear una comuna es efectivamente descentralizar. Las conclusiones, entonces, resumen los hallazgos e intentan resolver este y otros dilemas que sugieren su confrontación con otros casos nacionales.

\section{El modelo federal}

En la definición de federalismo hay cuatro concepciones generales: la del federalismo como alianza (foedus), o acuerdo entre gobiernos constitutivos (Gibson, 2004, pp. 4-6); la del federalismo como proceso o negociación continua entre intereses centrales y locales; la del federalismo como un régimen descentralizado; y la del federalismo como régimen democrático.

En relación al federalismo como alianza, Riker (1975, p. 101) considera a este sistema como un pacto de mutua confianza entre unidades constituyentes para crear un gobierno central y para definir atribuciones entre ambos niveles. Elazar (1987, pp. 33-37) señala que el federalismo surge de la necesidad de un conjunto de unidades políticas de asociarse en forma permanente, pero limitada, para avanzar objetivos comunes, mientras se mantienen separadas de manera de preservar sus respectivos intereses e identidades. Distintamente, en un régimen unitario la descentralización del poder es un asunto de gracia (don) del gobierno central, no un derecho que se desprende de los términos originales de la alianza entre gobiernos constituyentes. Para Elazar la lógica de la descentralización en un Estado unitario implica una organización jerárquica; en cambio, la descentralización en un régimen federal corresponde a una matriz donde no existe la figura piramidal de niveles de poder, sino solo arenas más grandes o más pequeñas de toma de decisiones políticas para distintos propósitos. Es precisamente esta concepción la que explica el uso del término "devolution" como sinónimo de descentralización; 
donde el gobierno federal "devuelve" atribuciones a las unidades constituyentes originalmente depositarias de soberanía.

En su segunda concepción, para Riker (1975, p. 103) "el federalismo es esencialmente el proceso de federalizar”. En la misma línea Falleti (2005, p. 328) seńala que el régimen de gobierno interior de un país no debiera considerarse como una fotografía instantánea de la organización del Estado, sino como un proceso continuo de reforma, donde la autoridad es distribuida y redistribuida mediante una negociación continua entre los intereses centralistas y los subnacionales (Rodden, 2004, p. 489); fenómeno que se aplica tanto a un país unitario como a uno federal, y donde la diferencia es el resultado final relativamente centralista del primero.

En efecto, producto de una reforma descentralizadora emerge una nueva distribución de poder que a menudo mejora la posición de los actores subnacionales en relación a los actores que operan a nivel central. En lo sucesivo los actores subnacionales comienzan a presionar por reformas adicionales y más poder. Esta dinámica es anticipada por los actores centralistas, para quienes cualquier renuncia de poder hoy desatará una demanda creciente mañana, lo que hace más costosa y difícil cualquier concesión inicial (Lake y Rothchild, 2005).

Después de la reforma los actores centralistas tendrán fuertes incentivos para recentralizar o para buscar modos de beneficiarse del nuevo esquema descentralizado, por ejemplo transfiriendo a los gobiernos subnacionales los costos políticos de medidas impopulares o programas y políticas fallidas. Lo anterior en su momento comenzará a minar las supuestas ventajas de la descentralización y a generar un movimiento inverso de recentralización (Bednar, Eskridge Jr., y Ferejohn, 2001).

En relación a la tercera concepción, el federalismo como régimen descentralizado es un esquema de organización política en la cual las actividades de gobierno están divididas entre un gobierno federal y gobiernos constituyentes, de manera que cada nivel tiene a su cargo algunas actividades sobre las cuales toma decisiones que son finales (Riker, 1975, p. 101). En esta misma línea, Dahl (1986, p. 114) define federalismo como un sistema en el cual algunos asuntos son de exclusiva competencia de ciertas unidades locales, asuntos que están constitucionalmente fuera de la autoridad del gobierno nacional, y donde ciertos otros asuntos están constitucionalmente fuera del alcance de la autoridad de las unidades locales. Distintamente a un país unitario, en un régimen federal el demos formado por los ciudadanos de todo el país debe aceptar una agenda cerrada en áreas de política pública a nivel subnacional sobre las cuales no tiene atribuciones (Stepan, 2004, p. 48).

Mientras para algunos, la estructura federal es definitoria, Elazar (1987, pp. 10-13), en cambio, agrega a la existencia de un principio federal una práctica o proceso que refleje la realización de este principio. En efecto, hay muchos países que se han organizado de jure como federales, pero que de facto no lo son, como ha sido la práctica histórica de los países federales de América Latina; en cambio otros de jure son unitarios y de facto federales; como España e Italia. Para Cameron y Falleti (2005, p. 246) un elemento considerado clave en la definición de federalismo es que no sólo exista una estructura descentralizada del ejecutivo y del legislativo, sino 
también del poder judicial. Los tres poderes debieran tomar decisiones soberanas y finales sobre un conjunto definido de asuntos.

Sobre el efecto del régimen federal en la eficiencia y eficacia, Riker señala que el régimen -unitario o federal- afecta profundamente la forma en que se toman las decisiones (policy making process); sin embargo, en términos de resultados (policy outcomes) no hay diferencia significativa. Riker llega a esta conclusión después de comparar pares de países: Argentina y Chile, Malasia e Indonesia, Estados Unidos y Reino Unido, Australia y Nueva Zelanda, Nigeria y Ghana, y Yugoslavia y Polonia (Riker, 1975, pp. 143-145).

Finalmente, sobre la relación entre federalismo y democracia, Riker (1975, pp. 153-158) señala que buena parte de la discusión sobre federalismo -y por extensión sobre descentralizaciónes juicio normativo. Primero, el federalismo no promovería la democracia, puesto que basta con revisar el listado de países federales para darse cuenta que no todos ellos son democracias. Segundo, el federalismo no favorecería un mayor interés ciudadano en los gobiernos subnacionales, puesto que la evidencia demuestra que la atención principal siempre está puesta sobre las decisiones y acciones del gobierno central. Tercero - y siguiendo a Dahl— la libertad individual está mejor protegida en un régimen unitario donde la mayoría en una jurisdicción no puede contradecir a la mayoría nacional. En cualquier caso, Riker precisa que para todos los asuntos de interés nacional, la máxima libertad individual se alcanza cuando las decisiones políticas son tomadas a nivel nacional; mientras que para todos los temas de interés local, esto ocurre cuando las decisiones políticas son tomadas a nivel local.

Más optimista con respecto a los beneficios del federalismo, Stepan (2004, pp. 31-32) señala que sólo las democracias pueden ser federales. En efecto, las dictaduras no aceptan la autonomía política de los gobiernos subnacionales. Sin embargo, el caso contradictorio es el de China, donde progresivamente ha sido el Partido Comunista el que se ha descentralizado a nivel provincial y promovido un régimen de gobierno interior federal (Montinola, Qian, y Weingast, 1995). Al respecto, según Cameron y Falleti (2005, pp. 266-268) los federalismos latinoamericanos muestran que las autocracias y presidencialismos fuertes, o regímenes de partido único, han tendido a sobrepasar la institucionalidad federal. Pero que justamente, los espacios no completamente anulados de autonomía han servido después para favorecer la transición democrática, particularmente en los casos de Brasil y México.

Dahl (1986, pp. 114-116) se hace cargo de las supuestas debilidades democráticas de los regímenes federales en contrapunto a las ventajas del régimen unitario. Una de estas debilidades es que para garantizar la existencia de un proceso completamente democrático, el demos nacional debiera ejercer un control final sobre toda la agenda, y en un sistema federal esto no ocurre porque las unidades constituyentes tienen atribuciones soberanas sobre algunos sectores de esta agenda. En un país unitario, todas las unidades subnacionales (provincias y/o comunas) son creaciones del Congreso Nacional y/o del Ejecutivo, por lo tanto sujetos —al menos en principio- a su control. En un régimen unitario el gobierno central delega su autoridad a los gobiernos locales. Por lo tanto, el demos nacional tiene el control total de la agenda, incluida la posibilidad de descentralizar o recentralizar a discreción. Otra de las debilidades, es que el principio mayoritario aplicado a nivel nacional permite resolver los conflictos; sin embargo, 
en un sistema federal la mayoría nacional no puede prevalecer sobre una minoría que se ha constituido en mayoría en una unidad territorial específica; problema inexistente en un país unitario. Sin embargo, en el contexto federal, las unidades subnacionales tienen derecho al gobierno local, dado que fueron éstas las que originaron el gobierno federal y no al revés.

Según Dahl los regímenes unitarios no niegan per se los derechos ciudadanos. En otras palabras, un país federal no es necesariamente más democrático que un país unitario. Si un país unitario adopta un arreglo federal supranacional esto no produciría una pérdida democrática si ambos niveles son gobernados democráticamente, y si los derechos políticos primarios de los ciudadanos son respetados (Dahl, 1986, pp. 119-120).

En conclusión; primero, independiente de la existencia formal de un arreglo federal, la descentralización se origina en una alianza entre gobiernos constituyentes o en una iniciativa del gobierno central. Segundo, la negociación continua entre intereses centralistas e intereses subnacionales no es un proceso exclusivo de los regímenes federales, sino que también caracteriza la dinámica política de negociación centralización/descentralización dentro de un régimen unitario. Tal dinámica es un proceso de tiempo histórico que tiene su origen usualmente en el proceso de formación de un estado-nación. La descentralización, por tanto, no es un fenómeno exclusivamente contemporáneo. Tercero, la realización del principio federal -que existen áreas de poder asignadas a gobiernos que operan en distintos nieves- puede ser asumida de distinta manera tanto por países federales como por países unitarios. Cuarto, un país federal no es necesariamente más democrático que un país unitario.

\section{La idea del gobierno local}

Para el liberalismo clásico, los gobiernos locales son un requisito para el funcionamiento del sistema democrático. John Stuart Mill subraya como una de las razones del valor de las elecciones de las autoridades municipales el que promueven la virtud cívica en la práctica de la política y el gobierno. Para Jeremy Beetham existen tres objetivos de la democracia representativa en los que los gobiernos locales se desempeñan mejor que el gobierno central: primero, en términos de control político ciudadano (accountability), hay una mayor posibilidad para escrutar las acciones a nivel local; segundo, un gobierno local elegido responde de mejor manera a las necesidades de los ciudadanos que un gobierno central que actúa a nivel territorial; y tercero, se potencia una mejor representatividad (Andrew y Goldsmith, 1998, pp. 107-113).

Antes de que el Estado-nación se transformara en el foco de las ideas democráticas, la teoría política insistía que en que la unidad más apropiada para el gobierno republicano y democrático era la ciudad-Estado. Rousseau, por ejemplo, proponía que a mayor cantidad de ciudadanos, menor la influencia de cada ciudadano individual en la toma de decisiones. Si a mayor influencia del ciudadano más democrático es el sistema, entonces las unidades más pequeñas son más democráticas. Sin embargo, el dilema es que de acuerdo a este criterio, el sistema más democrático consistiría de una persona, lo que es un absurdo (Dahl, 1986, pp. 115-116); pero que sin embargo plantea que el gobierno comunal no es necesariamente el nivel óptimo; bien podría serlo un gobierno vecinal. 
Si consideramos que el criterio democrático se define por la capacidad del sistema de gobernar; es decir, de producir resultados valorados por la ciudadanía por consideraciones de eficacia o eficiencia, entonces se llegaría a la conclusión de que el gobierno central tiene mayores posibilidades de manejar de mejor forma una amplia variedad de asuntos. Por otro lado, Dahl (1986, pp. 121-122) plantea la cuestión de si existe o no el derecho al gobierno local; al mismo nivel del derecho a la libertad de expresión; es decir, un derecho moral tan básico que debiera ser garantizado constitucionalmente. El dilema surge cuando, por ejemplo, consideramos que el sistema escolar de una provincia perteneciente a un país federal está completamente colapsado ante la inoperancia del gobierno, ¿se justifica la intervención del gobierno federal? La respuesta puede ser afirmativa bajo consideraciones utilitaristas. Pero si ahora — continúa Dahl— suponemos que esta provincia es en realidad Francia y que el gobierno federal es la Unión Europea, entonces, podemos concluir rápidamente que Francia tiene el derecho a gobernarse a sí misma. En consecuencia, para Dahl (1986, p. 124) la pregunta sobre la unidad apropiada para el ejercicio pleno de la democracia no se puede responder desde la teoría política.

En la actualidad la prescripción de las ventajas de la descentralización están adscritas a la literatura sobre la calidad de la democracia, para la cual la recomendación de mayores grados de descentralización está fuertemente influida por supuestas ventajas ligadas a una mayor participación y mayores posibilidades de ejercer una ciudadanía política y social; elementos que se suman a las ventajas señaladas por el liberalismo clásico. Rhodes (2003), por ejemplo, rescata de la experiencia de presupuesto participativo de Porto Alegre el concepto de pragmatismo progresista, como una combinación de participación popular en las decisiones de gobierno con políticas fiscales prudentes.

Por otro lado, desde la teoría del régimen surge el modelo de la red, donde los actores, organizaciones y grupos de interés aprenden a cooperar entre ellos reconociendo su dependencia recíproca. La red sería una base informal de coordinación, donde no existe una estructura comprensiva de comando, pero donde el gobierno local ejerce una función articuladora central. Más que explotar los conflictos, la red suma aportes y crea sinergias para el desarrollo (Stoker, 1995, pp. 59-61). El modelo de la red estaría en la base del paradigma de la gobernanza local, promovido por estudiosos, organismos internacionales, ONG, gobiernos, etc.

Sin embargo, después de un par de décadas de vigencia de la actual ola descentralizadora a nivel mundial, existe una creciente desilusión y escepticismo con la virtudes de la descentralización y el federalismo, particularmente entre los países en desarrollo (Rodden, 2004, p. 481). Para Fox (1994) no basta con elegir alcaldes y gobernadores; la democratización local requiere la eliminación de prácticas políticas disruptivas, tales como: el fraude electoral, la exclusión arbitraria en registros de votantes, el voto no secreto, la intimidación de los votantes. En la misma línea, Goldfrank (2006) matiza el optimismo inicial referido a las posibilidades democráticas de los presupuestos participativos al revisar sistemáticamente la experiencia en una serie de países de América Latina. Montecinos (2006), por su parte, relativiza el alcance empoderante de las experiencias participativas de generación de los planes de desarrollo comunal en Chile. Adicionalmente, la corrupción sería mayor a nivel local, así como la posibilidad de captura, dada la adición de capas de gobierno y la expansión de áreas de responsabilidad compartida, que en definitiva reducen las posibilidades de control ciudadano (Rodden, 2004, p. 494). 
Con todo, el consenso actual no es un apoyo irrestricto a la descentralización, ni tampoco su negación. Los hallazgos de Tendler (1997, pp. 145-146), por ejemplo, señalan que la mejor calidad del gobierno es una dinámica de triple vía que involucra al gobierno local, a la sociedad civil y al gobierno central; este último con capacidad de monitorear los niveles subnacionales y fijar criterios y estándares de excelencia.

En resumen, para responder al supuesto potencial democrático de la descentralización, y tal como tempranamente concluyeran los influyentes estudios de Robert A. Dahl (2005)—originalmente publicado en 1961 - para el caso de New Haven y de Floyd Hunter (1953) para el caso de Atlanta sobre la cuestión de si el gobierno de las ciudades es poliárquico o elitista, es necesaria una respuesta empírica; es decir, en algunos casos la descentralización fortalecerá la democracia, mientras que en otros no lo hará.

\section{¿Qué es y qué no es descentralización?}

En un ampliamente citado estudio, Rondinelli, Nellis y Cheema (1983, pp. 13-28) definen descentralización como la transferencia de responsabilidad para el planeamiento, gestión, recolección de fondos y asignación de recursos desde el gobierno central. Para estos autores, dependiendo del organismo receptor de esta transferencia, existirían cuatro tipos principales de descentralización, a saber: desconcentración, delegación, devolución y privatización. La desconcentración se refiere a la transferencia de autoridad administrativa o responsabilidades dentro de los ministerios y agencias del gobierno central, lo que incluye sus oficinas instaladas al nivel territorial. La delegación corresponde a la transferencia de las responsabilidades de gestión sobre funciones específicamente definidas hacia organismos que están fuera de la estructura burocrática regular, o sólo indirectamente controlados por el gobierno central. Estos organismos tienen mínimos grados de discreción para llevar adelante estas tareas mientras la responsabilidad última sigue siendo del gobierno central; esto incluye empresas públicas o de propiedad mixta, organismos públicos autónomos (ejemplo, universidades públicas), u otras corporaciones públicas. En tanto la devolución es definida como la creación o el fortalecimiento financiero o legal de unidades subnacionales de gobierno, cuyas actividades están sustancialmente fuera del control directo del gobierno central, y que cuentan con atribuciones reservadas y la autoridad estatutaria para generar ingresos y decidir sus gastos. Finalmente, la privatización corresponde a la transferencia de funciones hacia organizaciones voluntarias o empresas privadas.

La definición anterior refleja un cierto consenso vigente en círculos académicos y políticos durante los 80. En efecto, esta definición comprehensiva de descentralización surge en los primeros años de la ola descentralizadora, que llegó de la mano con el proceso más amplio de reforma del Estado (confrontar Von Haldenwang, 1990). Sin embargo, el profuso estudio sobre el tema dio la oportunidad de una precisión conceptual que, en primer lugar, desligó la descentralización del fenómeno de la reforma del Estado, al apuntar correctamente que la descentralización no es un fenómeno exclusivo de las últimas décadas del siglo XX, sino en realidad un proceso dicotómico de descentralización/centralización, observable en distintos momentos históricos. 
En segundo lugar, el nuevo consenso académico apunta a que el único de los cuatro tipos principales de descentralización señalados por Rondinelli et al., que califica como descentralización propiamente tal, es el que estos autores etiquetaron como "devolución". En efecto, en la actualidad pocos podrían llamar descentralización a la privatización. En este último caso, se da una renuncia completa del Estado al desarrollo de un rol productivo o empresarial, el que en adelante es asumido por el sector privado. Con todo, son aún válidos los conceptos de delegación y desconcentración, aunque no correspondan a modalidades de descentralización.

Por ejemplo, a veces el término desconcentración aparece erróneamente como sinónimo de descentralización administrativa (Campbell, 2003; Grindle, 2000, p. 52); sin embargo, buena parte de la literatura claramente consiente en que la transferencia de fondos, poderes políticos y/o hacia cuerpos de gobierno en niveles inferiores no constituye descentralización, sino que desconcentración (Eaton, 2004b, p. 29; O’Neill, 2005, p. 17). Según Manor (1999, p. 5), la desconcentración permite al gobierno central trabajar más efectivamente en los niveles regionales y locales mientras mantiene el control total sobre estas arenas. La desconcentración supone una lógica burocrática weberiana (Boisier, 2000, p. 69) que intenta hacer al nivel central más gobernable y efectivo a través de una organización piramidal y jerárquica, lo que no significa empoderar a los niveles subnacionales en la toma de decisiones y el control ciudadano.

Por otro lado, cuando el gobierno central delega funciones en los municipios $-\mathrm{o}$ en otras entes, tales como ONG y corporaciones privadas - lo que en realidad está haciendo es externalizar una tarea que es de su responsabilidad, mientras mantiene el control de los términos, plazos, estándares de calidad, regulación, y financiamiento. A diferencia de la privatización, en la delegación el gobierno central mantiene un rol importante, mientras que los organismos receptores de las nuevas responsabilidades pueden ser públicos o privados.

El consenso actual, entonces, define descentralización como un conjunto de reformas dirigidas a la transferencia de responsabilidades, recursos o autoridad desde el gobierno central hacia gobiernos subnacionales autónomos (Falleti, 2005, p. 328; O’Neill, 2005, p. 16; Rodden, 2004, p. 482). Esta definición subraya tanto la distinción entre descentralización fiscal, administrativa y política, como el principio de que la lealtad primaria de las autoridades subnacionales no es hacia el gobierno central, sino a la ciudadanía local, o regional, según corresponda.

La descentralización funcional — también conocida como descentralización administrativa (Montero y Samuels, 2004, p. 7)— ocurre cuando el gobierno central transfiere la gestión de servicios o agencias públicas, programas, proyectos, o áreas completas de política pública (por ejemplo, salud, educación pública, vivienda, policía, desarrollo económico, turismo y/o protección social) a los gobiernos subnacionales (Falleti, 2005, p. 328). Esta transferencia debe incluir la atribución de diseñar, supervisar y financiar tales tareas, o por lo menos tener atribuciones sustantivas en estos asuntos.

O’Neill (2005, p. 17) precisa que existe descentralización fiscal cuando las autoridades subnacionales elegidas por la ciudadanía deciden el uso de transferencias no condicionadas y/o poseen la capacidad de imponer tributos. Sin embargo, haciendo el criterio un poco más 
elástico, podemos asimilar de manera segura la descentralización fiscal a un conjunto de políticas destinadas a incrementar los ingresos y/o la autonomía financiera de los gobiernos subnacionales (Falleti, 2005, p. 329).

La descentralización política es un conjunto de reformas constitucionales o electorales diseñadas para crear o reactivar espacios inefectivos o congelados de representación política al nivel subnacional (Falleti, 2005, p. 329). La descentralización política ocurre cuando las reformas alteran la manera en que las autoridades subnacionales son constituidas, siendo la forma primigenia la elección ciudadana — no la designación — de las autoridades subnacionales (Eaton, 2004a, p. 222).

En resumen, dejando completamente fuera el fenómeno de la privatización, hay tres modalidades principales en que el gobierno central puede transferir poder, recursos y atribuciones a organismos públicos. Primero, la desconcentración, que implica el traspaso hacia abajo al interior de la estructura piramidal del gobierno central. Segundo, la delegación, que implica el traspaso hacia gobiernos subnacionales autónomos, pero donde el gobierno central mantiene un rol preponderante en la regulación y financiamiento, mientras que los gobiernos subnacionales se encargan fundamentalmente de la provisión de bienes y servicios públicos por encargo del gobierno central. Tercero, la descentralización propiamente tal, que implica la entrega de funciones a gobiernos subnacionales autónomos, y donde la tarea principal de diseñar, regular, monitorear, financiar e implementar es fundamentalmente de estos últimos.

\section{La agenda legislativa chilena: 1990-2008}

Esta evaluación de la agenda legislativa chilena parte de un análisis de todas las leyes aprobadas en el período comprendido entre el 11 de marzo de 1990 y el 10 de julio de 2008, a partir del cual se seleccionó un conjunto preliminar en función de sus descriptores y una revisión somera del articulado de las leyes, de manera de determinar su relevancia genérica en temas regionales y comunales (ver Anexo 1). Este ejercicio permitió el descarte de una serie de iniciativas cuya relevancia era tangencial, lo que hizo posible definir un primer conjunto de 174 leyes. El segundo paso fue la clasificación de estas leyes de acuerdo a las categorías establecidas en la sección anterior, para lo cual fue necesaria una revisión más exhaustiva.

De estas 174 leyes de impacto general en materias regionales y comunales se hizo un primer ejercicio de identificar aquellas que establecían incentivos territorialmente localizados. En efecto, se trata de leyes dirigidas a promover el desarrollo de zonas extremas o aisladas, las que podrían catalogarse como iniciativas centralistas de desarrollo regional y/o local, lo que incluye: tratamientos aduaneros y tributarios especiales, régimen de zona franca, programas de becas para habitantes de zonas específicas, o etnias territorialmente localizadas, subsidios laborales de zona, establecimiento de casinos, etc. Se trata de un número de 25 leyes, ${ }^{2}$ con lo que el número original de 174 se redujo a 149 leyes.

2 Las 25 leyes que otorgan beneficios territorialmente localizados son las siguientes: 19.149, 19.178, 19.206, $19.217,19.253,19.275,19.293,19.418,19.420,19.478,19.587,19.606,19.669,19.709,19.726,19.749$, $19.827,19.853,19.946,19.952,19.995,20.093,20.136,20.219$ у 20.268. 
Del análisis de estas 149 se observó que un número importante de ellas se refiere a modificaciones menores a otras leyes relevantes en términos de procedimientos, disposiciones transitorias y plazos, lo que se podría considerar como un afinamiento legislativo; por ejemplo, aquella que posterga la aplicación de reavalúos de bienes agrícolas (19.339), o la que modifica la fecha de celebración de las elecciones municipales (19.689), o la que extiende al año 2006 el esquema de redistribución del Fondo Común Municipal vigente en 2005 (20.075). Las leyes de afinamiento legislativo fueron 27 , por lo que el número de leyes relevantes se redujo de 149 a $122,{ }^{3}$ lo que constituye en definitiva el total de observaciones que este trabajo considera.

De este subconjunto de 122 leyes es notorio el bajo número de ellas que se originan en el Congreso versus aquellas que son ingresadas a tramitación mediante un mensaje presidencial. Se trata de 11 leyes, lo que representa el 9,7\% del total. En efecto, constitucionalmente (Chile, 1991, Art. 62) sólo el Presidente de la República puede presentar iniciativas de ley en lo referente a la división político-administrativa del país, lo que incluye la creación de una nueva región o comuna, así como las iniciativas en materia financiera que puedan afectar el presupuesto de la nación. Ejemplos importantes de esto último, son en lo que concierne a los gobiernos regionales y locales las asignaciones del Fondo Nacional de Desarrollo Regional (FNDR) y las modificaciones al Fondo Común Municipal (FCM). Adicionalmente, las atribuciones fiscales del Presidente son bastante significativas vis a vis el poder legislativo. Cuando el Presidente envía anualmente al Congreso el proyecto de Presupuesto de la Nación, los parlamentarios no pueden incrementar o disminuir las distintas partidas de ingreso, sino que sólo reducir las partidas de gasto, con la excepción de los gastos definidos en otras leyes (Chile, 1991, Art. 64), tales como el FNDR y el FCM, y las transferencias para la salud y educación municipales. Esto significa que las transferencias del gobierno central a las municipalidades están altamente condicionadas por la voluntad presidencial, mientras que el Congreso tiene limitadas atribuciones. Finalmente, hay iniciativas legislativas adicionales relevantes a los gobiernos municipales y regionales que son de exclusiva prerrogativa presidencial, incluyendo: la imposición, abolición, exención, o condonación de contribuciones e impuestos de cualquier tipo; el establecimiento o abolición de agencias públicas en cualquier nivel de gobierno; la contratación de deuda pública; la condonación o reducción de cualquier obligación financiera cuyo beneficiario sea un organismo público (incluyendo los municipios); así como el establecimiento de escalas salariales y beneficios de los funcionarios públicos (Chile, 1991, Art. 62).

Este bajo número de proyectos de ley de origen parlamentario guarda relación con las limitadas atribuciones que tiene el Congreso chileno, lo que no necesariamente tiene que ver con el asunto particular de la descentralización y los temas regionales y locales. En Chile el Presidente no es meramente un colegislador, sino que el más importante legislador (Siavelis, 2000, pp. 21-23). En lo que concierne a la descentralización en Chile, por un lado, el Ejecutivo tiene amplio margen de maniobra en este ámbito y los parlamentarios deben esperar la iniciativa del Ejecutivo en lo más sustancioso de lo concerniente a temas regionales y locales, mientras que por el otro lado, su rol no es del todo marginal, puesto que un proyecto de ley del Ejecutivo

$3 \quad$ Las 27 leyes de afinamiento legislativo son: 18.982, 19.000, 19.034, 19.096, 19.150, 19.192, 19.194, 19.339, $19.362,19.380,19.468,19.575,19.689,19.714,19.770,19.806,19.892,19.990,20.002,20.008,20.024$, $20.075,20.085,20.114,20.131,20.150$ y 20.151 . 
puede ser de partida rechazado, o modificado sustancialmente, u obstruido y atrasado en su tramitación.

Existen dos indicadores que permiten medir este poder de los parlamentarios en el proceso legislativo: el número de trámites legislativos, y el número de meses que tarda un proyecto de ley desde que ingresa al Congreso hasta que es finalmente promulgado por el Presidente.

En relación al número de trámites, después de aprobar la idea de legislar, la cámara receptora debe aprobar el proyecto en votación particular, lo que implica que aprueba cada uno de los artículos del proyecto. Puede ocurrir que un proyecto es aprobado en general y en particular en la misma sesión. Luego de la votación en particular termina el primer trámite y el proyecto es enviado a la cámara revisora, donde opera el mismo mecanismo. Si la cámara revisora aprueba el proyecto sin introducir modificaciones, la iniciativa es enviada a la cámara de origen, la cual la envía al Presidente para su promulgación. Por tanto, el número mínimo de trámites es cuatro. Sin embargo, usualmente la cámara revisora introduce modificaciones, las cuales deben ser ratificadas por la cámara de origen. El proceso de ida y vuelta puede extenderse indefinidamente.

El gobierno central consulta y negocia sus proyectos de ley con una variedad de actores (burocracia, partidos, grupos de interés, etc.) antes de enviarlos al Congreso, de manera de evitar rechazos y demoras en el proceso legislativo; incluso algunos proyectos de ley ingresan al Congreso respaldados con un acuerdo pre-legislativo (Siavelis, 2002). Por ejemplo, el Acuerdo Político de 1991 fue firmado luego del rechazo inicial de la Derecha en el Congreso a la reforma regional y municipal, antes del reenvío del proyecto de ley por parte del ejecutivo. Más recientemente un acuerdo pre-legislativo similar se alcanzó para permitir la Ley de Rentas Municipales II.

En la práctica, el número promedio de trámites es de 5 , con una desviación estándar de 1 , lo que indica que la mayoría de las leyes fue procesada entre 4 y 6 trámites. Los proyectos de más difícil tramitación completaron hasta 8 trámites; entre ellos el Estatuto de Salud Primaria Municipal (19.378) en 39 meses de tramitación y la ley de Rentas Municipales I (19.388) en 47 meses. En tanto, la ley de Rentas Municipales II se completó en 6 trámites en un plazo de 40 meses. La ley de reforma de los gobiernos regionales (19.175) también se completó en 6 trámites, aunque su tiempo de aprobación fue relativamente breve (10 meses).

Específicamente en relación al número de meses de tramitación, algunas leyes demoran más que otras no sólo porque requieren más tiempo en su discusión y deliberación, sino que puede suceder que el proyecto se encuentre durmiendo en el Congreso, después que una moción de desacuerdo haya paralizado su procesamiento. El tiempo promedio de procesamiento de un proyecto de ley en las materias que nos interesan es de 18,4 meses, con una desviación estándar de 22,6 meses, lo que indica la amplia dispersión en el tiempo de tramitación.

Un ejemplo de un proyecto durmiendo fue el que creaba la comuna de Hualpén, en la Región del Bío-Bío. El proyecto ingresó al Senado en junio de 1995, siendo aprobado un año más tarde, por lo que fue enviado en su segundo trámite a la Cámara de Diputados, donde fue 
rechazado pocos días después. El proyecto durmió en el Congreso desde junio de 1996 a octubre de 2003, cuando el Presidente solicitó reconsiderar. Una comisión mixta finalmente aprobó la iniciativa en enero de 2004. La tramitación de este proyecto tardó 99 meses (8 años).

De acuerdo a los archivos legislativos, el intento de crear la comuna de Hualpén en 1995 había surgido después de la aprobación de las comunas de Padre Hurtado (19.340), Padre Las Casas (19.391), Concón (19.424), Chillán Viejo (19.434), San Rafael (19.435), San Pedro de La Paz (19.436) y Chiguayante (19.461), entre octubre de 1994 y junio de 1996. Sin embargo, cuando le tocaba el turno a Hualpén, varios diputados expresaron su descuerdo con la política del Gobierno de crear comunas sin primero definir un conjunto básico de criterios, tales como población, extensión territorial, etc. ${ }^{4}$ En consecuencia, ninguna nueva comuna fue creada en los siguientes nueve años hasta 2004, cuando cuatro nuevas comunas fueron establecidas: Hualpén (19.936), Alto Hospicio (19.943), Cholchol (19.944) y Alto Bío-Bío (19.959).

El total de 122 leyes puede clasificarse en 11 categorías generales.

Las leyes más numerosas corresponden a las del sector de educación municipal (24), las que modifican el esquema de ingresos municipales o comportan aportes adicionales a las arcas municipales (20), y las de creación de comunas (17); etiqueta que adiciona a las nuevas 11 comunas y 2 regiones creadas en el período 1990-2008, la modificación de límites intercomunales.

Es particularmente notoria la escasa aparición de iniciativas legislativas referidas a los gobiernos regionales; entre ellas la reforma constitucional (19.097), que a su vez permite la reforma a la Ley Orgánica Constitucional de Gobiernos Regionales -LOC GORE- (19.175); la ley que fija la planta de los servicios administrativos para cada uno de los GORE (19.379); la ley que modifica y expande marginalmente las funciones, estructura y recursos de los GORE (20.035); la enmienda constitucional que elimina la fijación en 13 del número de regiones (20.050); y las leyes que crean la Región de Los Ríos (20.174) y la Región de Arica-Parinacota (20.175). Se trata en definitiva de 7 leyes de un total de 122.

La más relevante de estas leyes de alcance regional es la que crea los consejos regionales elegidos indirectamente por la ciudadanía, a través de los colegios electorales provinciales, formados a su vez por los concejales comunales. Se trata de una institución inédita en la política chilena, cuyo efecto más notorio es reforzar la demanda descentralizadora, aunque en la práctica los consejos regionales tienen escasas atribuciones reales, mermadas por la inclusión del Intendente en su calidad de Presidente del Consejo. En efecto, las tareas de los consejos regionales están fundamentalmente concentradas en la planificación del desarrollo, sin ninguna función ejecutiva, y en la decisión sobre la asignación con estrechos márgenes de maniobra de una pequeña proporción de la inversión pública; la cual se ha ido incrementando con el tiempo, y que la retórica de los gobiernos de la Concertación subraya como un gran logro en el ámbito regional. La marginalidad de esta atribución y el hecho de que la función ejecutiva sea desempeñada

$4 \quad$ Ver: Congreso Nacional de Chile, Historia de la Ley, 19.936. 
Cuadro 1. Leyes agrupadas por categorías. Número de leyes, tiempo de tramitación y número de trámites legislativos.

\begin{tabular}{|c|c|c|c|c|}
\hline Categoría & Descripción & $\begin{array}{l}\mathrm{N}^{\circ} \\
\text { de leyes } \\
\text { por } \\
\text { categoría }\end{array}$ & $\begin{array}{l}\mathrm{N}^{\circ} \\
\text { promedio } \\
\text { de meses de } \\
\text { tramitación } \\
\text { legislativa } \\
\end{array}$ & $\begin{array}{l}\quad \mathrm{N}^{\circ} \\
\text { promedio } \\
\text { de trámites } \\
\text { legislativos }\end{array}$ \\
\hline $\begin{array}{l}\text { Reforma } \\
\text { Comprehensiva }\end{array}$ & $\begin{array}{l}\text { Incluye la reforma constitucional y reformas a } \\
\text { las leyes orgánicas constitucionales de gobiernos } \\
\text { regionales y de municipalidades ocurridas a } \\
\text { comienzos de la década, del } 90 \text {. }\end{array}$ & 3 & 6,7 & 6 \\
\hline $\begin{array}{l}\text { Creación de } \\
\text { comunas }\end{array}$ & $\begin{array}{l}\text { Crean comunas, regiones o modifican límites } \\
\text { inter-comunales. }\end{array}$ & 17 & 18 & 5 \\
\hline $\begin{array}{l}\text { Vivienda y } \\
\text { Urbanismo }\end{array}$ & $\begin{array}{l}\text { Definen competencias en vivienda social, planos } \\
\text { reguladores, aseo y ornato, atribuciones municipales } \\
\text { sobre edificaciones y bienes municipales. }\end{array}$ & 10 & 9 & 4,7 \\
\hline Educación & $\begin{array}{l}\text { Regulan el funcionamiento de la educación } \\
\text { pública municipal, incluidos sus estándares, } \\
\text { fiscalización, personal, escalas y aumentos } \\
\text { salariales. }\end{array}$ & 24 & 16 & 5,5 \\
\hline Salud & $\begin{array}{l}\text { Ídem al anterior, pero en lo referido al sistema } \\
\text { de salud primario municipal. }\end{array}$ & 10 & 10,4 & 5 \\
\hline Personal & $\begin{array}{l}\text { Establecen atribuciones a los alcaldes para } \\
\text { la gestión del personal municipal, así como } \\
\text { regulaciones adicionales, escalas y sueldos, } \\
\text { excluidos los sectores de educación y salud. }\end{array}$ & 16 & 11 & 5 \\
\hline Justicia & $\begin{array}{l}\text { Crean juzgados de policía local, de letras, y } \\
\text { salas de apelaciones en regiones. Adecuaciones } \\
\text { requeridas por la Reforma Procesal Penal. }\end{array}$ & 4 & 25,3 & 4,5 \\
\hline $\begin{array}{l}\text { Ingresos } \\
\text { Municipales }\end{array}$ & $\begin{array}{l}\text { Distribución del Fondo Común Municipal, } \\
\text { cambios en tasas de impuestos territoriales, y todas } \\
\text { aquellas modificaciones que alteran los ingresos } \\
\text { municipales y que no corresponden a transferencias } \\
\text { en las áreas de educación y salud. }\end{array}$ & 20 & 20,4 & 5 \\
\hline Atribuciones & $\begin{array}{l}\text { Definen competencias municipales adicionales; } \\
\text { por ejemplo, la gestión de bienes públicos, y el } \\
\text { rol de los municipios sobre las organizaciones } \\
\text { comunitarias. }\end{array}$ & 7 & 17,4 & 5,4 \\
\hline Elecciones & $\begin{array}{l}\text { Alteran las fechas, modalidad y sistema electoral } \\
\text { municipal; por ejemplo, la elección separada } \\
\text { de alcaldes y concejales. }\end{array}$ & 7 & 17,4 & 5,4 \\
\hline Autoridades & $\begin{array}{l}\text { Establecen regulaciones y requisitos para } \\
\text { alcaldes y concejales; por ejemplo, declaración } \\
\text { de patrimonio e intereses y el fuero maternal } \\
\text { para alcaldesas. }\end{array}$ & 4 & 45,8 & 6 \\
\hline
\end{tabular}

Fuente: Elaboración propia en base a Anexo 
por los intendentes como delegados presidenciales son, para Angell et al. (2001, p. 122), comprobación de que el término gobiernos regionales es un equívoco en Chile.

En relación al tiempo de tramitación, las categorías de más larga duración fueron las de autoridades y la de ingresos municipales. La primera estuvo fuertemente sesgada por tres leyes de lenta tramitación: la ley de bases de contratos administrativos (19.886), que demoró 44 meses; la que obliga la declaración de intereses a todas las autoridades políticas, incluidos alcaldes y concejales (19.653), que demoró 59 meses; y la ley que prescribe la declaración de patrimonio (20.088), y que demoró 76 meses. Con respecto a la categoría de ingresos municipales, el promedio en el tiempo de tramitación de 20 meses, refleja en parte la centralidad del asunto, fuertemente condicionado por las reformas más importantes en este ámbito (ley de Rentas I y II), así como las modificaciones al esquema de redistribución del Fondo Común Municipal.

De acuerdo a la definición de trabajo propuesta, del total de 122 leyes analizadas, 73 son descentralizadoras sea en su componente político, funcional o fiscal, o en alguna combinación de ellos. Sin embargo, 29 de estas 73 leyes contemplan componentes regulatorios ejercidos por el gobierno central, o en realidad se trata de leyes de delegación de funciones, que por lo tanto tienen un impacto por defecto o marginal en términos de descentralización.

Las leyes de descentralización política corresponden a las reformas al sistema electoral municipal (19.452 y 19.737), así como la que permite a los partidos políticos formar coaliciones y pactos ad-hoc para las elecciones municipales (19.452). Por su parte, las leyes de exclusiva descentralización funcional otorgan a las municipalidades nuevas atribuciones; tales como; desempeñar funciones en asuntos de vivienda social (19.022); mayor autonomía para los alcaldes en lo gestión de los recursos humanos del municipio (19.280); gestionar y disponer de terrenos y edificaciones municipales (19.425); extinguir obligaciones a los deudores municipales (19.602 y 19.756); incrementar las atribuciones del concejo municipal sobre los planos reguladores (19.778); y permitir a los alcaldes firmar contratos con otros organismos públicos en relación a obras públicas urbanas (19.865). Las leyes de descentralización fiscal son las que modifican el Fondo Común Municipal u otros componentes de los ingresos municipales no contemplados en el financiamiento de educación y salud.

En cambio la mayoría de las leyes de descentralización fiscal estuvieron dirigidas a resolver el déficit de la salud y la educación municipales. Específicamente algunas de ellas mejoraban los salarios y las condiciones laborales para profesores y personal no docente de las escuelas municipales (19.278; 19.464; y 19.873); fondos adicionales para cubrir la deuda previsional de los municipios (19.609); y salarios y beneficios para otros funcionarios municipales (19.760 y 19.813). Otras leyes de descentralización fiscal se refieren a reformas más comprehensivas de las finanzas municipales o regionales $(19.143 ; 19.506 ; 19.705 ; 19.816$; y 19.850).

Sin embargo, debe consignarse que en lo referido al financiamiento de la salud y educación municipal, su verdadero impacto descentralizador ocurre al margen. En efecto, siguiendo la conceptualización inicial, en Chile las funciones de salud y educación no han sido en rigor descentralizadas, sino que delegadas a los municipios. Dado que el gobierno central define las políticas en estos ámbitos, así como los estándares, y está a cargo de la fiscalización y el 
financiamiento, mientras que los municipios son meros prestadores de servicios, la responsabilidad principal sigue en manos del primero. ¿Por qué entonces tiene un impacto descentralizador? Porque dado que históricamente las transferencias del gobierno central han sido insuficientes para financiar la educación y salud, los municipios han debido echar mano a sus ingresos propios para cubrir parte de este déficit. De esta manera cualquier iniciativa que contribuya a reducir la carga financiera a los municipios en salud y educación, redunda en una mayor autonomía fiscal que les permite destinar los recursos liberados a otras áreas en las cuales los municipios sí son autónomos.

Lo anterior pone de relieve que la mayoría de las iniciativas de delegación (32) dicen relación con el financiamiento de la educación y la salud municipal, así como regulaciones al personal en estas áreas o nuevas disposiciones generales sobre su funcionamiento; por ejemplo, la obligatoriedad de la educación parvularia (19.771) y de un sistema centralizado de evaluación de desempeño de maestros de escuelas municipales (19.961).

Por otro lado, un número importante de leyes establecen regulaciones centralizadas para los gobiernos municipales en áreas que son de su competencia estrictamente descentralizada; por ejemplo, las regulaciones sobre la carrera funcionaria municipal (19.296 y 20.198), el funcionamiento de las asociaciones sindicales municipales, (19.475) y la regulación de asuntos electorales municipales (19.698).

Todas estas iniciativas de regulación en lo que respecta a los gobiernos locales se pueden considerar como obligaciones adicionales vinculantes, y no como mayores espacios de autonomía. Sin embargo, dado que tienen como objetivo mejorar el desempeño del sector público en general, pueden contribuir a una mayor eficiencia y eficacia en la provisión de bienes y servicios públicos valorados por la ciudadanía. Desde este punto de vista instrumental, que corresponde a la segunda fuente de legitimidad democrática de los gobiernos locales, en la medida que tales regulaciones logren el objetivo, entonces contribuyen a su fortalecimiento.

Aquellas leyes propiamente descentralizadoras que incluyen los tres componentes (fiscal, funcional y política) de manera simultánea son las que crean comunas o regiones, y las reformas comprehensivas que tuvieron lugar en 1991 y 1992. La creación de comunas puede considerarse como una forma efectiva de descentralización si se dan dos condiciones. Primero, si se reconoce la titularidad del derecho al gobierno local a una comunidad que se identifica como tal, y que con anterioridad formaba parte de una unidad mayor. Segundo, nuevamente desde el punto de vista instrumental, si la entrega de recursos, funciones y poder político se traduce en una mejor cantidad y mayor calidad de bienes y servicios públicos. Un municipio que genera representación política, pero que es incapaz de producir beneficios carece de legitimidad y en definitiva activa una tendencia opuesta de centralización.

En relación a la creación de regiones, su valoración es ambigua, porque por un lado corresponde a un proceso de desconcentración, en lo que respecta al intendente y su gabinete regional; y por el otro, corresponde a descentralización en lo que concierne a los consejeros regionales. Las limitadas atribuciones de los consejos regionales subrayan el dilema de cuánto poder, recursos y funciones se requieren para calificar un proceso como descentralizador. La 
comparación con otros países latinoamericanos nos puede conducir a negar la existencia en Chile de descentralización en el nivel regional. Sin embargo, en relación a su propia historia centralista, la existencia a partir de 1992 de los consejos regionales, elegidos indirectamente con escasas funciones, representa un paso en la dirección de la descentralización.

\section{Conclusiones}

¿Es democrático el régimen de gobierno interior chileno? El cuestionamiento no tiene que ver con la existencia de un sistema unitario. La respuesta no es normativa, sino empírica y referida a las imperfecciones de la democracia nacional y de la democracia local, además de la relativa ausencia de la democracia regional.

¿Tienen derecho los chilenos a la democracia regional? Sí lo tienen, y es un derecho que en la actualidad es en buena parte negado. Parafraseando a Riker, para todos los asuntos de alcance regional la máxima libertad se alcanza cuando las decisiones son tomadas a nivel regional. Desde el punto de vista utilitario, existe una serie de asuntos que pueden ser mejor gestionados a nivel regional en términos de eficiencia y eficacia. Sin embargo, el deficiente proceso de delegación de la educación y la salud a los municipios; sin asegurar el adecuado financiamiento, ha comprometido seriamente la capacidad de los municipios de desarrollar aquellas otras funciones en las que son autónomos del gobierno central y, por lo tanto, sujetos al control democrático ciudadano. Por lo tanto, una reforma descentralizadora a nivel regional que no desarrolle capacidades y entregue los recursos requeridos pone en riesgo la eventual democracia regional plena y genera tendencias centralizadoras.

Nuestra definición de trabajo señalaba que la descentralización es un conjunto de reformas dirigidas a la transferencia de responsabilidades, recursos o autoridad desde el gobierno central hacia gobiernos subnacionales autónomos. Desde este punto vista, sin contar con la restauración de las elecciones municipales y la creación de los consejos regionales, el proceso descentralizador chileno ha sido muy limitado. En parte ha influido que el principal afectado -el gobierno central- sea quien controle la iniciativa legislativa, y con ello el ritmo y la profundidad de las reformas. En parte también, ha influido que la retórica oficialista presente como descentralización a iniciativas que no lo son, y que buena parte de la opinión pública acepte estos sucedáneos.

Vista la experiencia chilena, nuestra definición inicial requiere un afinamiento que puede ser relevante para el estudio de otros casos nacionales a nivel latinoamericano y que releve la importancia de los procesos de regulación centralizada sobre funciones municipales autónomas y que, además, incorpore la experiencia común de la creación de municipios y/o regiones. Considerando la anterior, entonces, se define descentralización como aquellas reformas institucionales dirigidas a la transferencia de responsabilidades, recursos o autoridad desde el gobierno central hacia gobiernos subnacionales autónomos, tendientes a asegurar la representación democrática de comunidades territorialmente localizadas y una más eficiente y eficaz provisión de bienes y servicios públicos. 


\section{Referencias bibliográficas}

Andrew, C. \& Goldsmith, M. (1998). From local government to local governance and beyond. International Political Science Review, 19, 2, 100-117.

Angell, A.; Lowden, P. \& Thorp, R. (2001). Decentralizing development. The political economy of institutional change in Colombia and Chile. Oxford: Oxford University Press.

Bednar, J.; Eskridge Jr., W. N. \& Ferejohn, J. (2001). A political theory of federalism. En J. Ferejohn, J. Rakove \& J. Riley (Eds.), Constitutional culture and democratic rule (pp. 223-267). New York:: Cambridge University Press.

Boisier, S. (2000). Chile: la experiencia regionalista del gobierno militar. Estudios Sociales, $104,2,43-76$.

Cameron, M. A. \& Falleti, T. G. (2005). Federalism and the subnational separation of powers. Publius: The Journal of Federalism, 35, 2, 245-271.

Campbell, T. (2003). The quiet revolution. Decentralization and the rise of political participation in Latin American cities. Pittsburgh: The University of Pittsburgh Press.

Dahl, R. A. (1986). Democracy, liberty, and equality. Oslo: Norwegian University Press.

Dahl, R. A. (2005). Who governs. Democracy and power in an American city. Second Ed. New Haven: Yale University Press.

Eaton, K. (2004a). Designing subnational institutions, regional and municipal reforms in postauthoritarian Chile. Comparative Political Studies, 37, 2, 218-244.

Eaton, K. (2004b). Politics beyond the capital. The design of subnational institutions in South America. Stanford, CA: Stanford University Press.

Elazar, D. J. (1987). Exploring federalism. Tuscaloosa: University of Alabama Press.

Falleti, T. (2005). A sequential theory of decentralization: Latin American cases in comparative perspective. American Political Science Review, 99, 3, 327-346.

Fox, J. (1994). Latin America's emerging local politics. Journal of Democracy, 5, 2, 105-116.

Gibson, E. L. (2004). Federalism and democracy. Theoretical connections and cautionary insights. En E. L. Gibson (Ed.), Federalism and democracy in Latin America (pp. 1-28). Baltimore, MD: The Johns Hopkins University Press.

Goldfrank, B. (2006). Los procesos de "presupuesto participativo" en América Latina: Éxito, fracaso y cambio. Revista de Ciencia Politica, 26, 2, 3-28.

Grindle, M. S. (2000). Audacious reforms. Institutional invention and democracy in Latin America. Baltimore, MD: The Johns Hopkins University Press.

Hunter, F. (1953). Community power structure. A study of decision makers. Chapel Hill, NC: University of North Carolina Press.

Lake, D. A. \& Rothchild, D. (2005). Territorial decentralization and civil war settlements. En P. G. Roeder \& D. Rothchild (Eds.), Sustainable peace: Power and democracy after civil wars (pp. 109-132). Ithaca, NY: Cornell University Press,.

Manor, J. (1999). The political economy of democratic decentralization. Washington, DC: The World Bank.

Mardones, R. (2006). Descentralización y transición en Chile. Revista de Ciencia Politica, 26, 1: 3-24.

Mardones, R. (2007). The congressional politics of decentralization: the case of Chile. Comparative Political Studies, 40, 3, 333-358. 
Montecinos, E. (2006). Descentralización y democracia en Chile: análisis sobre la participación ciudadana en el presupuesto participativo y el plan de desarrollo comunal. Revista de Ciencia Política, 26, 2, 191-208.

Montero, A. P. \& Samuels, D. J. (2004). The political determinants of decentralization in Latin America. Causes and consequences. En A. P. Montero \& D. J. Samuels (Eds.), Decentralization and democracy in Latin America (pp. 3-32). Notre Dame, IN: University of Notre Dame Press.

Montinola, G.; Qian, Y. \& Weingast, B. R. (1995). Federalism Chinese style: the political basis for economic success in China. World Politics, 48, 50-81.

O'Neill, K. (2005). Decentralizing the state: elections, parties, and local power in the Andes. New York: Cambridge University Press.

República de Chile (1991). Constitución política de la República de Chile. 1980. (actualizada por ley 20.162 del 16 de febrero de 2007). Rescatado de http://www.bcn.cl/lc/cpolitica/ index_html, el 19 de mayo de 2007.

Rhodes, S. D. (2003). Progressive pragmatism as a governance model. An in-depth look at Porto Alegre, Brazil, 1989-2000. En S. Eckstein \& T. Wickham-Crowley (Eds.), What justice? Whose justice? Fighting for fairness in Latin America (pp. 217-232). Berkeley, CA: University of California Press.

Riker, W. H. (1975). Federalism. En F. I. Greenstein \& N. W. Polsby (Eds.), Handbook of political science. (pp. 93-172). Reading, MA: Addison-Wesley.

Rodden, J. (2004). Comparative federalism and decentralization. On meaning and measurement. Comparative Politics, 36, 4, 481-500.

Rondinelli, D. A.; Nellis, J. R. \& Cheema, G. S. (1983). Decentralization in developing countries: a review of recent experience. Staff Working Papers, 581. Washington: The World Bank.

Siavelis, P. (2000). President and congress in postauthoritarian Chile. Institutional constraints to democratic consolidation. University Park, PA: Penn State University Press.

Siavelis, P. (2002). Exaggerated presidentialism and moderate presidents: executive-legislative relations in Chile. En S. Morgenstern \& B. Nacif (Eds.), Legislative politics in Latin America (pp. 79-113). New York: Cambridge University Press.

Stepan, A. (2004). Toward a new comparative politics of federalism, multinationalism, and democracy. En E. L. Gibson (Ed.), Federalism and democracy in Latin America (pp. 2984). Baltimore, MD: The Johns Hopkins University Pres.

Stoker, G. (1995). Regime theory and urban politics. En D. Judge, G. Stoker \& H. Wolman (Eds.), Theories of urban politics (pp. 54-71). London: SAGE Publications.

Tendler, J. (1997). Good government in the tropics. Baltimore, MD: The Johns Hopkins University Press.

Von Haldenwang, C. (1990). Hacia un concepto politológico de la descentralización del Estado en América Latina. EURE, 26, 50, 61-77. 
Anexo 1. 122 leyes de relevancia regional y/o comunal promulgadas en fecha que se indica. Tiempo de tramitación, número de trámites legislativos y clasificación según componentes principales. Período de cobertura: 11 de marzo de 1990 al 11 de julio de 2008 .

\begin{tabular}{|c|c|c|c|c|c|c|c|c|c|c|}
\hline \multirow{2}{*}{ Ley $\mathrm{N}^{\circ}$} & \multirow{2}{*}{$\begin{array}{l}\text { Fecha } \\
(\mathrm{m} / \mathrm{d} / \mathrm{a})\end{array}$} & \multirow{2}{*}{ Materia } & \multirow{2}{*}{ Meses } & \multirow{2}{*}{ Trámites } & \multirow{2}{*}{\begin{tabular}{|c|}
$\begin{array}{c}\text { Descon- } \\
\text { centra- } \\
\text { ción }\end{array}$ \\
\end{tabular}} & \multirow{2}{*}{$\begin{array}{c}\text { Delega- } \\
\text { ción }\end{array}$} & \multirow{2}{*}{$\begin{array}{l}\text { Regu- } \\
\text { lación }\end{array}$} & \multicolumn{3}{|c|}{ Descentralización } \\
\hline & & & & & & & & Política & Funcional & Fiscal \\
\hline 18.992 & $8 / 16 / 90$ & Creación de comunas & 2.6 & 4 & & & $\sqrt{ }$ & & & \\
\hline 19.022 & $12 / 27 / 90$ & Vivienda y Urbanismo & 1.5 & 4 & & & & & $\sqrt{ }$ & \\
\hline 19.054 & $4 / 13 / 91$ & Educación & 12.5 & 6 & & $\sqrt{ }$ & & & & \\
\hline 19.057 & $2 / 20 / 91$ & Vivienda y Urbanismo & 4.6 & 4 & & & & & $\sqrt{ }$ & \\
\hline 19.070 & $7 / 1 / 91$ & Educación & 8.5 & 6 & & $\sqrt{ }$ & & & & $\sqrt{ }$ \\
\hline 19.097 & $11 / 12 / 91$ & Reforma comprehensiva & 5.7 & 5 & & & & $\sqrt{ }$ & $\sqrt{ }$ & $\sqrt{ }$ \\
\hline 19.130 & $3 / 19 / 92$ & Reforma comprehensiva & 4.2 & 7 & & & & $\sqrt{ }$ & $\sqrt{ }$ & $\sqrt{ }$ \\
\hline 19.143 & $6 / 17 / 92$ & Ingresos municipales & 12.9 & 5 & & & & & & $\sqrt{ }$ \\
\hline 19.146 & $6 / 24 / 92$ & Elecciones & 0.7 & 4 & & & $\sqrt{ }$ & & & \\
\hline 19.165 & $9 / 1 / 92$ & Personal & 14.4 & 5 & & & $\sqrt{ }$ & & & \\
\hline 19.175 & $11 / 11 / 92$ & Reforma comprehensiva & 10.1 & 6 & & & & $\sqrt{ }$ & $\sqrt{ }$ & \\
\hline 19.180 & $12 / 7 / 92$ & Personal & 6.8 & 8 & & & $\sqrt{ }$ & & & \\
\hline 19.211 & $4 / 26 / 93$ & Personal & 1.8 & 4 & & & & & & \\
\hline 19.236 & $8 / 21 / 93$ & Justicia & 15.7 & 4 & $\sqrt{ }$ & & & & & \\
\hline 19.251 & $10 / 2 / 93$ & Salud & 1.7 & 4 & & $\sqrt{ }$ & & & & $\sqrt{ }$ \\
\hline 19.278 & $12 / 13 / 93$ & Educación & 0.9 & 4 & & $\sqrt{ }$ & & & & $\sqrt{ }$ \\
\hline 19.280 & $12 / 16 / 93$ & Personal & 14.1 & 6 & & & & & $\sqrt{ }$ & \\
\hline 19.296 & $3 / 14 / 94$ & Personal & 21.8 & 5 & & & $\sqrt{ }$ & & & \\
\hline 19.298 & $3 / 12 / 94$ & Justicia & 5.9 & 4 & $\sqrt{ }$ & & & & & \\
\hline 19.340 & $10 / 17 / 94$ & Creación de comunas & 9.4 & 4 & & & & $\sqrt{ }$ & $\sqrt{ }$ & $\sqrt{ }$ \\
\hline 19.345 & $11 / 7 / 94$ & Personal & 17.5 & 5 & & & $\sqrt{ }$ & & & \\
\hline 19.373 & $2 / 8 / 95$ & Creación de comunas & 2.9 & 4 & & & $\sqrt{ }$ & & & \\
\hline 19.378 & $4 / 13 / 95$ & Salud & 39 & 8 & & $\sqrt{ }$ & & & $\sqrt{ }$ & $\sqrt{ }$ \\
\hline 19.379 & $4 / 3 / 95$ & Personal & 28.3 & 7 & $\sqrt{ }$ & & & & & \\
\hline 19.388 & $5 / 30 / 95$ & Ingresos municipales & 46.9 & 8 & & & & & $\sqrt{ }$ & $\sqrt{ }$ \\
\hline 19.391 & $6 / 2 / 95$ & Creación de comunas & 16.5 & 7 & & & & $\sqrt{ }$ & $\sqrt{ }$ & $\sqrt{ }$ \\
\hline 19.395 & $7 / 17 / 95$ & Ingresos municipales & 3.2 & 4 & & & $\sqrt{ }$ & & & \\
\hline 19.398 & $8 / 4 / 95$ & Educación & 3.1 & 5 & & $\sqrt{ }$ & & & & $\sqrt{ }$ \\
\hline 19.405 & $8 / 31 / 95$ & Salud & 3.5 & 5 & & $\sqrt{ }$ & $\sqrt{ }$ & & & $\sqrt{ }$ \\
\hline 19.410 & $9 / 2 / 95$ & Educación & 16 & 6 & & $\sqrt{ }$ & $\sqrt{ }$ & & & $\sqrt{ }$ \\
\hline 19.414 & $10 / 3 / 95$ & Salud & 21.6 & 5 & $\sqrt{ }$ & & & & & \\
\hline 19.424 & $12 / 28 / 95$ & Creación de comunas & 4.9 & 5 & & & & $\sqrt{ }$ & $\sqrt{ }$ & $\sqrt{ }$ \\
\hline 19.425 & $11 / 27 / 95$ & Atribuciones & 15.8 & 6 & & & & & $\sqrt{ }$ & \\
\hline 19.434 & $12 / 29 / 95$ & Creación de comunas & 14.6 & 5 & & & & $\sqrt{ }$ & $\sqrt{ }$ & $\sqrt{ }$ \\
\hline 19.435 & $12 / 29 / 95$ & Creación de comunas & 14.6 & 5 & & & & $\sqrt{ }$ & $\sqrt{ }$ & $\sqrt{ }$ \\
\hline 19.436 & $12 / 29 / 95$ & Creación de comunas & 14.6 & 5 & & & & $\sqrt{ }$ & $\sqrt{ }$ & $\sqrt{ }$ \\
\hline 19.452 & $4 / 16 / 96$ & Elecciones & 8.2 & 8 & & & & $\sqrt{ }$ & & \\
\hline 19.461 & $6 / 28 / 96$ & Creación de comunas & 19.2 & 5 & & & & $\sqrt{ }$ & $\sqrt{ }$ & $\sqrt{ }$ \\
\hline 19.464 & $8 / 5 / 96$ & Educación & 8.9 & 5 & & $\sqrt{ }$ & & & & $\sqrt{ }$ \\
\hline 19.475 & $10 / 4 / 96$ & Personal & 5.1 & 4 & & & $\sqrt{ }$ & & & \\
\hline
\end{tabular}




\section{Continuación}

\begin{tabular}{|c|c|c|c|c|c|c|c|c|c|c|}
\hline \multirow{2}{*}{ Ley $\mathrm{N}^{\circ}$} & \multirow{2}{*}{ Fecha } & \multirow{2}{*}{ Materia } & \multirow{2}{*}{ Meses } & \multirow{2}{*}{ Trámites } & \multirow{2}{*}{$\begin{array}{c}\text { Descon- } \\
\text { centra- } \\
\text { ción }\end{array}$} & \multirow{2}{*}{$\begin{array}{l}\text { Delega- } \\
\text { ción }\end{array}$} & \multirow{2}{*}{$\begin{array}{l}\text { Regu- } \\
\text { lación }\end{array}$} & \multicolumn{3}{|c|}{ Descentralización } \\
\hline & & & & & & & & Política & Funcional & Fisca \\
\hline 19.483 & $11 / 30 / 96$ & Atribuciones & 7 & 5 & & & $\sqrt{ }$ & & & \\
\hline 19.504 & $5 / 31 / 95$ & Educación & 5.1 & 5 & & $\sqrt{ }$ & & & & $\sqrt{ }$ \\
\hline 19.506 & $7 / 30 / 97$ & Ingresos municipales & 22.8 & 6 & & $\sqrt{ }$ & & & & $\sqrt{ }$ \\
\hline 19.509 & $8 / 12 / 97$ & Educación & 1.1 & 4 & & $\sqrt{ }$ & & & $\sqrt{ }$ & \\
\hline 19.526 & $11 / 17 / 97$ & Elecciones & 29.6 & 6 & & & & $\sqrt{ }$ & $\sqrt{ }$ & \\
\hline 19.529 & $11 / 14 / 97$ & Personal & 2.2 & 5 & & & & & & $\sqrt{ }$ \\
\hline 19.543 & $12 / 24 / 97$ & Personal & 8.8 & 4 & & & $\sqrt{ }$ & & & \\
\hline 19.546 & $2 / 2 / 98$ & Salud & 3.4 & 5 & & $\sqrt{ }$ & & & & $\sqrt{ }$ \\
\hline 19.550 & $2 / 3 / 98$ & Educación & 2.7 & 4 & & $\sqrt{ }$ & & & & $\sqrt{ }$ \\
\hline 19.560 & $4 / 21 / 98$ & Ingresos municipales & 78.3 & 5 & & & & & & $\sqrt{ }$ \\
\hline 19.583 & $9 / 14 / 98$ & Vivienda y urbanismo & 26.8 & 6 & & & $\sqrt{ }$ & & & \\
\hline 19.592 & $11 / 30 / 98$ & Justicia & 8.8 & 5 & $\sqrt{ }$ & & & & & \\
\hline 19.600 & $12 / 31 / 98$ & Ingresos municipales & 0.5 & 4 & & & $\sqrt{ }$ & & & \\
\hline 19.602 & $3 / 25 / 99$ & Atribuciones & 46.2 & 6 & & & & & $\sqrt{ }$ & \\
\hline 19.607 & $5 / 14 / 99$ & Salud & 23.7 & 5 & & $\sqrt{ }$ & $\sqrt{ }$ & & $\sqrt{ }$ & $\sqrt{ }$ \\
\hline 19.609 & $6 / 2 / 99$ & Personal & 7.4 & 6 & & & & & & $\sqrt{ }$ \\
\hline 19.648 & $12 / 2 / 99$ & Educación & 36.9 & 6 & & $\sqrt{ }$ & $\sqrt{ }$ & & & \\
\hline 19.653 & $12 / 14 / 99$ & Autoridades & 58.9 & 8 & & & $\sqrt{ }$ & & & \\
\hline 19.667 & $3 / 10 / 00$ & Vivienda y urbanismo & 3.8 & 5 & & & $\sqrt{ }$ & & & \\
\hline 19.676 & $5 / 29 / 00$ & Ingresos municipales & 94.7 & 6 & & & $\sqrt{ }$ & & & \\
\hline 19.688 & $8 / 5 / 00$ & Educación & 73 & 7 & & $\sqrt{ }$ & $\sqrt{ }$ & & & \\
\hline 19.698 & $9 / 30 / 00$ & Elecciones & 1.9 & 4 & & & $\sqrt{ }$ & & & \\
\hline 19.701 & $12 / 28 / 00$ & Ingresos municipales & 48.4 & 5 & & & $\sqrt{ }$ & & & \\
\hline 19.704 & $12 / 28 / 00$ & Ingresos municipales & 7.3 & 5 & & & & & $\sqrt{ }$ & $\sqrt{ }$ \\
\hline 19.710 & $1 / 20 / 01$ & Atribuciones & 10 & 5 & & & $\sqrt{ }$ & & $\sqrt{ }$ & \\
\hline 19.727 & $5 / 3 / 01$ & Vivienda y urbanismo & 1.4 & 6 & & & $\sqrt{ }$ & & & \\
\hline 19.731 & $6 / 14 / 01$ & Personal & 7.4 & 4 & & & & & & $\sqrt{ }$ \\
\hline 19.737 & $7 / 6 / 01$ & Elecciones & 48.6 & 6 & & & & $\sqrt{ }$ & & \\
\hline 19.754 & $9 / 21 / 01$ & Personal & 13.2 & 5 & & & & & $\sqrt{ }$ & \\
\hline 19.756 & $9 / 13 / 01$ & Ingresos municipales & 2.8 & 4 & & & & & $\sqrt{ }$ & \\
\hline 19.760 & $10 / 23 / 01$ & Salud & 3.2 & 4 & & $\sqrt{ }$ & & & & $\sqrt{ }$ \\
\hline 19.771 & $11 / 15 / 01$ & Educación & 72.2 & 6 & & $\sqrt{ }$ & $\sqrt{ }$ & & & \\
\hline 19.777 & $12 / 5 / 01$ & Justicia & 70.6 & 5 & $\sqrt{ }$ & & & & & \\
\hline 19.778 & $12 / 10 / 01$ & Vivienda y urbanismo & 8.2 & 4 & & & & & $\sqrt{ }$ & \\
\hline 19.780 & $11 / 30 / 01$ & Ingresos municipales & 1 & 4 & & & & & $\sqrt{ }$ & $\sqrt{ }$ \\
\hline 19.803 & $4 / 27 / 02$ & Personal & 13.2 & 4 & & & $\sqrt{ }$ & & & \\
\hline 19.813 & $6 / 25 / 02$ & Salud & 1.4 & 5 & & $\sqrt{ }$ & & & & $\sqrt{ }$ \\
\hline 19.816 & $8 / 7 / 02$ & Ingresos municipales & 3.9 & 5 & & & & & & $\sqrt{ }$ \\
\hline 19.845 & $12 / 14 / 02$ & Ingresos municipales & 0.4 & 4 & & & $\sqrt{ }$ & & & \\
\hline 19.846 & $1 / 4 / 03$ & Atribuciones & 21.5 & 6 & & & & & $\sqrt{ }$ & \\
\hline 19.850 & $1 / 7 / 03$ & Ingresos municipales & 0.9 & 4 & & & & & & $\sqrt{ }$ \\
\hline 19.852 & $1 / 8 / 03$ & Autoridades & 3.8 & 5 & & & $\sqrt{ }$ & & & \\
\hline 19.864 & $4 / 8 / 03$ & Educación & 42.7 & 5 & & $\sqrt{ }$ & $\sqrt{ }$ & & $\sqrt{ }$ & \\
\hline
\end{tabular}


Continuación

\begin{tabular}{|c|c|c|c|c|c|c|c|c|c|c|}
\hline \multirow{2}{*}{ Ley $\mathrm{N}^{\circ}$} & \multirow{2}{*}{ Fecha } & \multirow{2}{*}{ Materia } & \multirow{2}{*}{ Meses } & \multirow{2}{*}{$\begin{array}{c}\text { Trámi- } \\
\text { tes }\end{array}$} & \multirow{2}{*}{$\begin{array}{c}\text { Descon- } \\
\text { centra } \\
\text { ción } \\
\end{array}$} & \multirow{2}{*}{$\begin{array}{c}\text { Delega- } \\
\text { ción }\end{array}$} & \multirow{2}{*}{$\begin{array}{l}\text { Regu- } \\
\text { lación }\end{array}$} & \multicolumn{3}{|c|}{ Descentralización } \\
\hline & & & & & & & & Política & Funcional & Fiscal \\
\hline 19.865 & $4 / 1 / 03$ & Vivienda y Urbanismo & 26.5 & 5 & & $\sqrt{ }$ & & & $\sqrt{ }$ & \\
\hline 19.873 & $5 / 29 / 03$ & Educación & 4.7 & 6 & & $\sqrt{ }$ & & & & $\sqrt{ }$ \\
\hline 19.876 & $5 / 22 / 03$ & Educación & 8.6 & 6 & & $\sqrt{ }$ & $\sqrt{ }$ & & & \\
\hline 19.884 & $8 / 5 / 03$ & Elecciones & 25 & 5 & & & & & $\sqrt{ }$ & \\
\hline 19.886 & $7 / 30 / 03$ & Autoridades & 44.4 & 5 & & & $\sqrt{ }$ & & & \\
\hline 19.926 & $12 / 31 / 03$ & Ingresos municipales & 6.9 & 6 & & & & & & $\sqrt{ }$ \\
\hline 19.933 & $2 / 12 / 04$ & Educación & 1 & 5 & & $\sqrt{ }$ & $\sqrt{ }$ & & & \\
\hline 19.936 & $3 / 13 / 04$ & Creación de comunas & 99.2 & 5 & & & & $\sqrt{ }$ & $\sqrt{ }$ & $\sqrt{ }$ \\
\hline 19.939 & $2 / 13 / 04$ & Vivienda y Urbanismo & 8.3 & 5 & & & & & $\sqrt{ }$ & \\
\hline 19.943 & $4 / 22 / 04$ & Creación de comunas & 7.6 & 4 & & & & $\sqrt{ }$ & $\sqrt{ }$ & $\sqrt{ }$ \\
\hline 19.944 & $4 / 22 / 04$ & Creación de comunas & 7.6 & 4 & & & & $\sqrt{ }$ & $\sqrt{ }$ & $\sqrt{ }$ \\
\hline 19.958 & $7 / 17 / 04$ & Elecciones & 8 & 5 & & & $\sqrt{ }$ & & & \\
\hline 19.959 & $7 / 21 / 04$ & Creación de comunas & 10.6 & 6 & & & & $\sqrt{ }$ & $\sqrt{ }$ & $\sqrt{ }$ \\
\hline 19.961 & $8 / 14 / 04$ & Educación & 9.3 & 5 & & $\sqrt{ }$ & $\sqrt{ }$ & & & \\
\hline 19.972 & $9 / 16 / 04$ & Ingresos municipales & 5.2 & 5 & & & & & & $\sqrt{ }$ \\
\hline 19.979 & $11 / 6 / 04$ & Educación & 33.9 & 8 & & & $\sqrt{ }$ & & & \\
\hline 20.006 & $3 / 22 / 05$ & Educación & 7.6 & 5 & & $\sqrt{ }$ & $\sqrt{ }$ & & & \\
\hline 20.033 & $7 / 1 / 05$ & Ingresos municipales & 39.7 & 6 & & & & & & $\sqrt{ }$ \\
\hline 20.035 & $7 / 1 / 05$ & Atribuciones & 27.8 & 6 & & & & & $\sqrt{ }$ & $\sqrt{ }$ \\
\hline 20.041 & $7 / 14 / 05$ & Creación de comunas & 12.2 & 4 & & & $\sqrt{ }$ & & & \\
\hline 20.050 & $8 / 26 / 05$ & Creación de comunas & 61.7 & 8 & & & & $\sqrt{ }$ & & \\
\hline 20.088 & $1 / 5 / 06$ & Autoridades & 76.1 & 6 & & & $\sqrt{ }$ & & & \\
\hline 20.103 & $5 / 16 / 06$ & Vivienda y urbanismo & 3.7 & 4 & & & $\sqrt{ }$ & & & \\
\hline 20.121 & $9 / 4 / 06$ & Atribuciones & 4 & 4 & & $\sqrt{ }$ & $\sqrt{ }$ & & & \\
\hline 20.135 & $12 / 13 / 06$ & Personal & 9.7 & 4 & & & & & $\sqrt{ }$ & \\
\hline 20.157 & $1 / 5 / 07$ & Salud & 2.2 & 4 & & $\sqrt{ }$ & & & & $\sqrt{ }$ \\
\hline 20.158 & $12 / 29 / 06$ & Educación & 0.5 & 5 & & $\sqrt{ }$ & & & & $\sqrt{ }$ \\
\hline 20.159 & $1 / 25 / 07$ & Educación & 2.6 & 5 & & $\sqrt{ }$ & & & & $\sqrt{ }$ \\
\hline 20.174 & $5 / 4 / 07$ & Creación de comunas & 3.7 & 5 & & & & $\sqrt{ }$ & $\sqrt{ }$ & $\sqrt{ }$ \\
\hline 20.175 & $11 / 4 / 07$ & Creación de comunas & 3.9 & 5 & & & & $\sqrt{ }$ & $\sqrt{ }$ & $\sqrt{ }$ \\
\hline 20.198 & $9 / 7 / 07$ & Personal & 3.9 & 4 & & & $\sqrt{ }$ & & & \\
\hline 20.201 & $20 / 6 / 07$ & Educación & 23 & 8 & & & $\sqrt{ }$ & & & \\
\hline 20.118 & $29 / 9 / 07$ & Vivienda y Urbanismo & 4.9 & 4 & & & & & & $\sqrt{ }$ \\
\hline 20.237 & $24 / 12 / 07$ & Ingresos municipales & 25.5 & 4 & & & & & & $\sqrt{ }$ \\
\hline 20.244 & $19 / 1 / 08$ & Educación & 7.5 & 4 & & $\sqrt{ }$ & & & & $\sqrt{ }$ \\
\hline 20.247 & $24 / 1 / 08$ & Educación & 3.7 & 5 & & & & & & $\sqrt{ }$ \\
\hline 20.250 & $9 / 2 / 08$ & Salud & 4 & 5 & & & $\sqrt{ }$ & & & $\sqrt{ }$ \\
\hline 20.269 & $27 / 6 / 08$ & Ingresos municipales & 0.7 & 4 & & & & & & $\sqrt{ }$ \\
\hline 20.280 & $4 / 7 / 08$ & Ingresos municipales & 5.9 & 5 & & & & & $\sqrt{ }$ & $\sqrt{ }$ \\
\hline
\end{tabular}

Fuente: Elaboración propia en base a listados de todas las leyes aprobadas por el gobierno, disponibles en la sección "proceso legislativo" del sitio Web del Ministerio Secretaría General de la Presidencia, en http:// www.minsegpres.cl/portal/menu/agenda_legislativa.html 